GUSTAVO JORGE SILVA

\title{
Acordes dissonantes: \\ A fragmentação institucional das políticas monetária e cambial brasileiras na Grande Recessão
}

\author{
Dissertação de Mestrado \\ Orientador: Professor Dr. Luís Fernando Massonetto
}

UNIVERSIDADE DE SÃO PAULO

FACULDADE DE DIREITO

São Paulo - SP

2019 

GUSTAVO JORGE SILVA

\title{
Acordes dissonantes: \\ A fragmentação institucional das políticas monetária e cambial brasileiras na Grande Recessão
}

\begin{abstract}
Dissertação apresentada à Banca Examinadora do Programa de Pós-Graduação em Direito, da Faculdade de Direito da Universidade de São Paulo, como exigência parcial para obtenção do título de Mestre em Direito, na área de concentração Direito Econômico e Financeiro, sob a orientação do Professor Dr. Luís Fernando Massonetto.
\end{abstract}

UNIVERSIDADE DE SÃO PAULO

FACULDADE DE DIREITO

São Paulo - SP 
Autorizo a reprodução e a divulgação total e parcial deste trabalho, por qualquer meio convencional ou eletrônico, para fins de estudo e pesquisa, desde que citada a fonte.

\author{
Catalogação da Publicação
}

Serviço de Biblioteca e Documentação

Faculdade de Direito da Universidade de São Paulo

Silva, Gustavo Jorge

Acordes dissonantes: A fragmentação institucional das políticas monetária e cambial brasileiras na Grande Recessão ; Gustavo Jorge Silva ; orientador Luís Fernando Massonetto -- São Paulo, 2019.

183

Dissertação (Mestrado - Programa de Pós-Graduação em Direito Direito Econômico, Financeiro e Tributário) - Faculdade de Direito, Universidade de São Paulo, 2019.

1. Moeda. 2. Política Monetária. 3. Política Cambial. 4. Banco Central do Brasil. 5. Conselho Monetário Nacional. I. Massonetto, Luís Fernando, orient. II. Título. 
Nome: SILVA, Gustavo Jorge.

Título: Acordes dissonantes: A fragmentação institucional das políticas monetária e cambial brasileiras na Grande Recessão.

Dissertação apresentada à Banca Examinadora do Programa de Pós-Graduação em Direito, da Faculdade de Direito da Universidade de São Paulo, como exigência parcial para obtenção do título de Mestre em Direito, na área de concentração Direito Econômico e Financeiro, sob a orientação do Professor Dr. Luís Fernando Massonetto.

Depósito em 2019. Aprovado em:

\section{BANCA EXAMINADORA}

Prof. Dr.:

Instituição:

Julgamento:

Assinatura:

Prof. Dr.:

Instituição:

Julgamento:

Assinatura:

Prof. Dr.:

Instituição:

Julgamento:

Assinatura: 

“... und alle Wissenschaft wäre überflüssig, wenn die Erscheinungsform und das Wesen der Dinge unmittelbar zusammenfielen" Karl Marx 



\section{AGRADECIMENTOS}

Agradeço aos meus pais, Júlia e Jorge, que encararam todas as dificuldades, sem nunca me deixar faltar um lápis, um caderno ou um abraço, e sempre me incentivaram a estudar e conhecer mais um pouco. Esse trabalho também é de vocês, da primeira até a última palavra.

Agradeço ao meu já há alguns anos orientador, Professor Luís Fernando Massonetto, que me viu acertar e errar, mas sempre me ajudou a refletir e a procurar formas de refinar meu pensamento. Foi também gratificante poder, pela segunda vez, coordenar o Grupo de Estudos Direito e Regulação do Capitalismo (GEDIRC), grupo de estudos pelo qual eu tenho tanto carinho e que efetivamente me aproximou dos debates sobre Direito Econômico e Economia Política. Obrigado por acreditar no meu projeto e no meu trabalho.

Aos Professores José Tadeu de Chiara e Fernando Monteiro Rugitsky, por terem aceitado participar do meu exame de qualificação e terem me fornecido indicações muito relevantes, que permitiram que eu conseguisse estruturar esta Dissertação.

Sou muito grato também aos meus colegas do GEDIRC dos tempos de Graduação, que acabaram se tornando também meus colegas de orientação nesse Mestrado e me ajudaram com valiosos conselhos e dicas de bibliografia. Agradeço a todos os amigos e amigas que me prestaram assistência e me renderam apoio incondicional nesses últimos anos e, especialmente, nos últimos meses.

Agradeço a todos que trataram do tema desta Dissertação antes de mim. Tudo o que essas páginas dizem paga tributo ao pensamento de vocês.

Meu desejo é que este trabalho, de alguma forma, sirva para que este país cresça e se desenvolva com inclusão. Que possamos ser muitos mais nos cursos de Pós-Graduação, Mestrados e Doutorados, discutindo abertamente as leis e a política sobre as quais foi erguido o Brasil, para que possamos melhorá-lo, sem que haja retrocesso, repressão ou obscurantismo. 


\section{RESUMO}

SILVA, Gustavo Jorge. Acordes dissonantes: A fragmentação institucional das políticas monetária e cambial brasileiras na Grande Recessão. fls. 183. Mestrado em Direito. Faculdade de Direito, Universidade São Paulo. São Paulo. 2019.

A presente Dissertação tem por objetivo expor, do ponto de vista jurídico, a particularidade das medidas tomadas em relação à gestão das políticas monetária e cambial no Brasil entre setembro de 2008, data que marca o início da fase mais aguda da Grande Recessão, e agosto de 2011, ocasião em que o conjunto de medidas que veio a formar o que ficou conhecido como Nova Matriz Econômica passou a se estruturar. Ao longo desse período de pouco menos de três anos, é notável uma substancial fragmentação da gestão dessas políticas, até então formalmente concentrada no Conselho Monetário Nacional e no Banco Central do Brasil. Embora o mandato legal dessas duas instituições sobre as políticas monetária e cambial não tenha cessado em momento algum, chama a atenção que a atuação delas nesses campos tenha sido ladeada pela de outros agentes como o Banco Nacional de Desenvolvimento Econômico e Social; o Banco do Brasil S.A.; a Caixa Econômica Federal; a Secretaria do Tesouro Nacional; o Ministério da Fazenda (sucedido pelo atual Ministério da Economia); e mesmo a Presidência da República e agentes privados como o Fundo Garantidor de Créditos. A Dissertação indica que essa fragmentação se deu por conta da insuficiência dos instrumentos típicos de política monetária e cambial aplicados pelo Conselho Monetário Nacional e pelo Banco Central do Brasil desde 1999, quando da adoção do chamado "tripé" macroeconômico. Argumenta-se que o quadro normativo e institucional vigente no Brasil até a Grande Recessão - que, em grande medida, segue em vigência continha limitações estruturais, que se tornaram evidentes diante dos efeitos da Grande Recessão. Entende-se que essas limitações possuem causas históricas e dadas por uma dinâmica que contrapõe interesses domésticos e externos no processo de criação das normas e instituições de política monetária e de política cambial. Faz-se uso de uma metodologia tomada das Relações Internacionais para estruturar esse entendimento. A conclusão aponta para a necessidade de que seja aberto o debate sobre as normas e instituições relacionadas à política monetária e à política cambial no Brasil.

PALAVRAS-CHAVE: 1. Moeda. 2. Política Monetária. 3. Política Cambial. 4. Banco Central do Brasil. 5. Conselho Monetário Nacional. 


\begin{abstract}
SILVA, Gustavo Jorge. Acordes dissonantes: A fragmentação institucional das políticas monetária e cambial brasileiras na Grande Recessão. p. 183. Master in Law. Faculty of Law, University of São Paulo. São Paulo. 2019.

The purpose of this Dissertation is to show, from the legal standpoint, the particularity of the measures adopted regarding the management of monetary and exchange rate policies in Brazil between September 2008, following the beginning of the most acute phase of the Great Recession, and August 2011, when the set of measures that came to form what became known as New Economic Matrix began to be structured. Throughout this period of just under three years, a substantial fragmentation of the management of these policies, thitherto formally concentrated in the National Monetary Council and the Central Bank of Brazil, is remarkable. Although the legal mandate of these two institutions over monetary and exchange rate policies has not ceased at any time, it is striking that their performance in these fields has been flanked by other agents such as the Banco Nacional de Desenvolvimento Econômico e Social; the Banco do Brasil S.A.; the Caixa Econômica Federal; the National Treasury Secretariat; the Ministry of Finance (succeeded by the current Ministry of Economy); and even the Presidency of the Republic and private agents such as the Fundo Garantidor de Créditos. The Dissertation denotes that this fragmentation occurred due to the insufficiency of the typical monetary and exchange rate policy instruments applied by the National Monetary Council and the Central Bank of Brazil since 1999, when the so-called macroeconomic "tripod" was adopted. It is argued that the normative and institutional framework prevailing in Brazil until the Great Recession - which is still largely in force contained structural limitations, which became evident in the face of the effects of the Great Recession. It is understood that these limitations have historical causes and are given by a dynamic that opposes domestic and foreign interests in the process of creating norms and institutions of monetary and foreign exchange policy. A methodology taken from International Relations is used to structure this understanding. The conclusion indicates the need to open the debate on norms and institutions related to monetary and foreign exchange policy in Brazil.
\end{abstract}

KEYWORDS: 1. Money. 2. Monetary Policy. 3. Foreign exchange policy. 4. Central Bank of Brazil. 5. National Monetary Council. 



\section{SUMÁRIO}

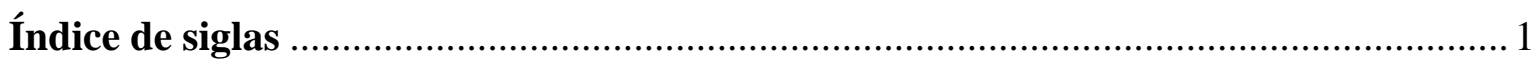

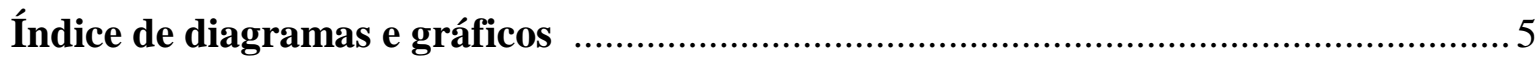

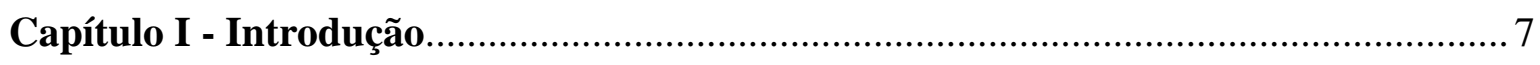

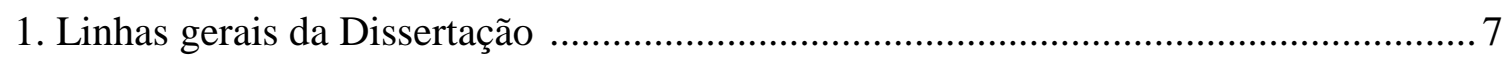

Capítulo II - Aspectos metodológicos e conceituais ................................................... 13

2. Metodologia e pressupostos doutrinários de Direito Econômico ................................ 13

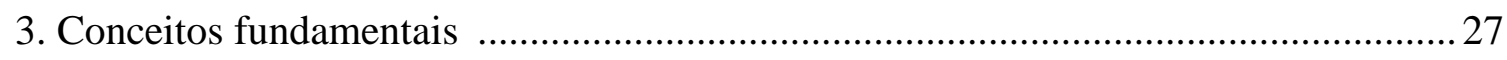

Capítulo III - Políticas monetária e cambial brasileiras antes da crise de 2008 .......... 43

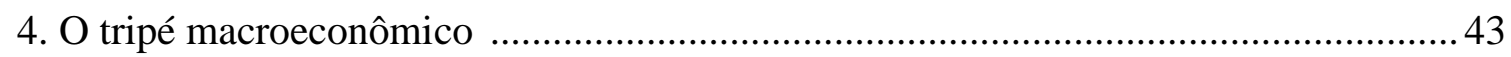

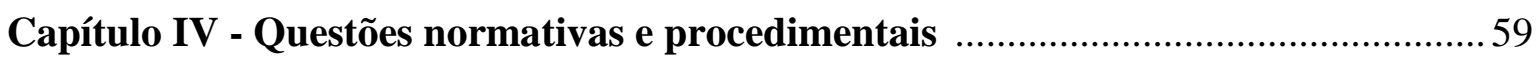

5. Reações dos países centrais à crise de 2008 e reflexos na periferia ............................59

6. A reação fragmentada das instituições brasileiras....................................................... 77

7. As limitações dos regimes monetário e cambial no Brasil ......................................... 95

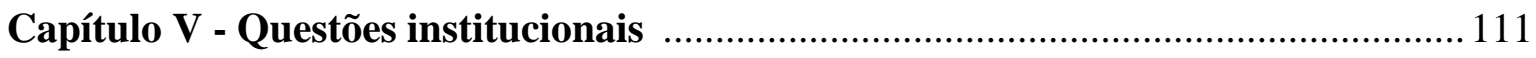

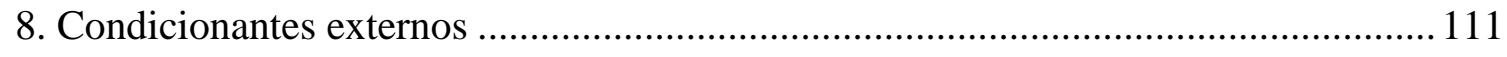

9. Políticas monetária e cambial brasileiras até a década de 1980 ................................ 127

10. Formação do atual padrão institucional .............................................................. 145

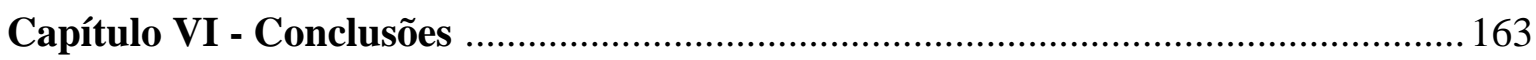

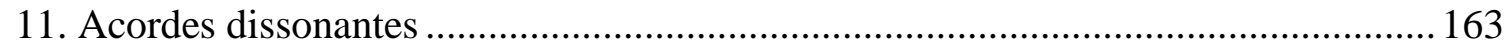

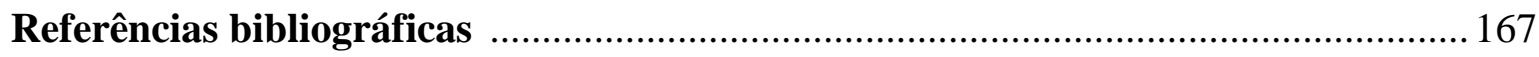





\section{Índice de siglas}

ADR

BACEN

BB

BC

BCB

BCBS

BCE

BID

BIRD

BIS

BM\&FBovespa Bolsa de Valores, Mercadorias e Futuros de São Paulo

BNDE

BNDES

BPM5

BPM6

BRICS

BRL

BTN

CACEX

CAMOB

CARED

CDO

CDS

CEF

CEPAL

CIP

CMN

American depositary receipt

Banco Central do Brasil

Banco do Brasil S.A.

Banco Central do Brasil (ocorre apenas em citações)

Comitê de Supervisão Bancária da Basileia

Banco Central Europeu

Banco Interamericano de Desenvolvimento

Banco Mundial

Banco de Compensações Internacionais

Banco Nacional de Desenvolvimento Econômico de Investimentos do Fundo Monetário Internacional

Real brasileiro

Bônus do Tesouro Nacional

Carteira de Comércio Exterior

Carteira de Mobilização Bancária

Carteira de Redescontos

Collateralized Debt Obligations

Credit Default Swaps

Caixa Econômica Federal das Nações Unidas

Conselho Interministerial de Preços

Conselho Monetário Nacional
Banco Central do Brasil (ocorre apenas em uma citação)

Banco Nacional de Desenvolvimento Econômico e Social

Quinta edição do Manual de Balanço de Pagamentos e Posição Internacional de Investimentos do Fundo Monetário Internacional

Sexta edição do Manual de Balanço de Pagamentos e Posição Internacional

Grupo formado por Brasil, Rússia, Índia, China e África do Sul

Comissão Econômica para a América Latina e o Caribe da Organização 


\begin{tabular}{|c|c|}
\hline $\mathrm{CNC}$ & Consolidação das Normas Cambiais \\
\hline COMOC & Comissão Técnica da Moeda e do Crédito \\
\hline COPOM & Comitê de Política Monetária \\
\hline COREMEC & $\begin{array}{l}\text { Comitê de Regulação e Fiscalização dos Mercados Financeiro, de Capitais, } \\
\text { de Seguros, de Previdência e Capitalização }\end{array}$ \\
\hline CUT & Central Única dos Trabalhadores \\
\hline CVM & Comissão de Valores Mobiliários \\
\hline $\mathrm{Cz} \$$ & Cruzeiro \\
\hline DSGE & Dinâmico Estocástico de Equilíbrio Geral \\
\hline EUA & Estados Unidos da América \\
\hline Fannie Mae & Federal National Mortgage Association \\
\hline FEBRABRAN & Federação Brasileira de Bancos \\
\hline FED & Federal Reserve \\
\hline FGC & Fundo Garantidor de Créditos \\
\hline FGV & Fundação Getúlio Vargas \\
\hline FIESP & Federação das Indústrias do Estado de São Paulo \\
\hline FIPE & Fundação Instituto de Pesquisas Econômicas \\
\hline FMI & Fundo Monetário Internacional \\
\hline Freddie Mac & Federal Home Loan Mortgage Corporation \\
\hline FSE & Fundo Social de Emergência \\
\hline G10 & $\begin{array}{l}\text { Grupo que reúne Alemanha, Bélgica, Canadá, Estados Unidos da América, } \\
\text { França, Itália, Japão, Países Baixos, Reino Unido, Suécia e Suíça }\end{array}$ \\
\hline $\mathrm{G} 20$ & Neste trabalho, equivale a G20 financeiro \\
\hline G20 financeiro & $\begin{array}{l}\text { Grupo que reúne os dezenove países com as maiores economias do mundo } \\
\text { - África do Sul, Alemanha, Arábia Saudita, Argentina, Austrália, Brasil, } \\
\text { Canadá, China, Coreia do Sul, Estados Unidos da América, França, Índia, } \\
\text { Indonésia, Itália, Japão, México, Reino Unido, Rússia e Turquia - e a } \\
\text { União Europeia. }\end{array}$ \\
\hline G8 & $\begin{array}{l}\text { Grupo que reúne o grupo das sete maiores economias avançadas do mundo } \\
\text { - Alemanha, Canadá, Estados Unidos da América, França, Itália, Japão e } \\
\text { Reino Unido - e a Rússia }\end{array}$ \\
\hline GATT & Acordo Geral sobre Tarifas e Comércio \\
\hline IBGE & Instituto Brasileiro de Geografia e Estatística \\
\hline IDR & International depositary receipt \\
\hline
\end{tabular}


IFC

IFI

IGP-M

II PND

IOF

IPC

IPCA

IPC-MTb

IPMF

IS-LM

LDO

LRF

LTN

NDF

OCDE

OECE

OIG

OMC

ONU

ORTN

OTN

PAEG

PAI

PIB

PIIGS

PND

PPC

PTAX

QE

RMCCI

SAMBA
International Finance Corporation

Instituição Financeira Internacional

Índice Geral de Preços de Mercado

II Plano Nacional de Desenvolvimento

Imposto sobre Operações de Crédito, Câmbio e Seguros

Índice de Preços ao Consumidor

Índice Nacional de Preços ao Consumidor Amplo

Índices de Preços ao Consumidor do Ministério do Trabalho

Imposto Provisório sobre Movimentação Financeira

Investment Saving-Liquid preference Money Supply

Lei de Diretrizes Orçamentárias

Lei de Responsabilidade Fiscal

Letra do Tesouro Nacional

Non-deliverable forward

Organização para a Cooperação e Desenvolvimento Econômico

Organização Europeia de Cooperação Econômica

Organização Intergovernamental

Organização Mundial do Comércio

Organização das Nações Unidas

Obrigação Reajustável do Tesouro Nacional

Obrigação do Tesouro Nacional

Plano de Ação Econômica do Governo

Programa de Ação Imediata

Produto Interno Bruto

Portugal, Irlanda, Itália, Grécia e Espanha

Programa Nacional de Desestatização

Paridade de Poder de Compra

Taxa média de câmbio Real/Dólar divulgada pelo Banco Central do Brasil Afrouxamento quantitativo (quantitative easing)

Regulamento do Mercado de Câmbio e Capitais Internacionais

Stochastic Analytical Model with a Bayesian Approach 
Selic Sistema Especial de Liquidação e de Custódia

SEPT

Serviço de Estatística da Previdência e Trabalho

SFN

Sistema Financeiro Nacional

SMI

Sistema Monetário Internacional

STN

Secretaria do Tesouro Nacional

SUMOC

Superintendência da Moeda e do Crédito

SUSEP

Superintendência de Seguros Privados

TR

Taxa Referencial

URV

Unidade Real de Valor

USD

Dólar americano

VAR

Vetores Autorregressivos 


\section{Índice de diagramas e gráficos}

Diagrama 1 - Modelo de jogo de dois níveis para esta Dissertação

Diagrama 2 - Tríade impossível 35

Gráfico 1 - Fed funds rate (janeiro/ 2006 - janeiro/ 2016) 64

Gráfico 2 - Taxas de juros básicas dos países centrais comparadas (Janeiro/1999 Maio/2013)

Gráfico 3 - Fluxo líquido de capital dirigido aos mercados emergentes (bilhões de Dólares)

Gráfico 4 - Taxa de câmbio real de moedas da América Latina em relação ao Dólar (USD/x)

Gráfico 5 - Termos de troca de países latino-americanos $(2000=100)$ 73

Gráfico 6 - Reservas internacionais de países latino-americanos (janeiro/2009 = 100) .....74

Gráfico 7 - Selic nominal (\%) - 05/12/2007 - 18/01/2012 .79

Gráfico 8 - Alíquota efetiva de recolhimento compulsório do Brasil .79

Gráfico 9 - Taxa de câmbio 2008-2011 (BRL/USD). .85

Gráfico 10 - Reservas internacionais (milhões de USD) 1994-2012. 86

Gráfico 11 - Migração, integração financeira e abertura comercial, 1880-1996 (indexado $1900=100)$ 112

Gráfico 12 - Modelo IS-LM

Gráfico 13 - Saldo anual dos recursos de capitais via Anexo IV (milhões de USD) 


\section{CAPÍTULO I - Introdução}

\section{Linhas gerais da Dissertação}

Em 15 de setembro de 2008, a Lehman Brothers Holdings Inc., entidade controladora do banco Lehman Brothers, apresentou pedido de proteção para o banco sob o Capítulo 11 da Lei de Falências americana perante a vara de falências do Distrito Sul de Nova Iorque, dando início ao maior processo do gênero da história americana ${ }^{1}$. À época, o Banco Lehman Brothers contava com 158 anos de existência, mas teve a continuidade do seu funcionamento profundamente abalada pela crise do subprime que afetava o sistema financeiro dos Estados Unidos da América (EUA) desde 2007.

Na forma do Direito americano, a proteção do Capítulo 11 garante à empresa em crise a possibilidade de seguir atuando em sua atividade econômica enquanto elabora um plano de recuperação de sua capacidade de operação e renegocia suas dívidas com seus credores. Em relação ao Direito brasileiro, essa proteção tem sua natureza jurídica comparável à do instituto da Recuperação Judicial.

Apesar de não representar a falência da instituição financeira ${ }^{2}$, o episódio acabou por mudar o patamar da crise americana na medida em que a dificuldade operacional de um grande banco aumentou significativamente o risco sistêmico para todo setor financeiro americano, que, por sua centralidade, passou a comprometer a atividade financeira global.

A Grande Recessão que atingiu os países centrais depois desse episódio caracterizouse por uma redução brutal na liquidez da economia e, consequentemente, um alto endividamento de setores relevantes da sociedade que não tinham mais acesso ao crédito, além de desemprego em níveis persistentemente altos. Nesse contexto, soluções de política econômica que extrapolavam a ortodoxia construída em relação à dinâmica global da moeda e do crédito passaram a ganhar espaço ${ }^{3}$.

Essa Dissertação de Mestrado parte da dinâmica relacionada às políticas monetária e cambial do Brasil no período situado entre a apresentação do pedido de proteção pela

\footnotetext{
${ }^{1}$ Disponível em < http://www.sandiegouniontribune.com/sdut-lehman-brothers-files-chapter-11-protection2008sep15-story.html >. Acesso em 31 de maio de 2019.

${ }^{2} \mathrm{O}$ pedido de falência veio a ser apresentado pelo Lehman Brothers Holdings Inc. em 6 de março de 2012.

${ }^{3}$ Apresentei isso também em SILVA (2018c).
} 
Lehman Brothers Holdings Inc., que trataremos como marco inicial da Grande Recessão, e o início da aplicação do conjunto de medidas macroeconômicas que convencionou-se chamar de Nova Matriz Econômica, adotadas a partir de meados de 2011, tendo como limite temporal o início do ciclo de redução da taxa básica de juros brasileira em 31 de agosto de 2011. Portanto, a pesquisa irá procurar indicar as peculiaridades da política monetária adotada principalmente entre setembro de 2008 e agosto de 2011.

Trata-se de período durante o qual o exercício das políticas monetária e cambial foi marcado por uma série de peculiaridades que serviram para compensar algumas insuficiências que haviam se tornado evidentes no quadro regulatório no qual estava baseada a política econômica brasileira desde 1999, ocasião em que foram adotados o regime cambial de câmbio flutuante e o regime monetário de metas de inflação, bem como a taxa básica de juros passou a ser percebida como o instrumento essencial para a gestão da moeda no País. Chama atenção nesse período, por um lado, a adoção de medidas fora da ortodoxia, envolvendo inclusive controles de capital ${ }^{4}$ e medidas macroprudenciais, para manutenção da estabilidade do valor do Real no plano doméstico e também no mercado de câmbio internacional, e, por outro lado, o envolvimento de muitas instituições e autoridades na adoção dessas medidas, gerando o que chamaremos de fragmentação institucional das políticas monetária e cambial.

Do ponto de vista legal, desde a entrada em vigor da Lei ${ }^{\circ} 4.595$, de 31 de dezembro de 1964, o Conselho Monetário Nacional (CMN) detém o mandato legal para formulação das políticas monetária e cambial o Banco Central do Brasil (BACEN) possui o mandato legal para execução dessas políticas. É isso que torna particularmente notável o engajamento de múltiplos órgãos em matérias de política monetária e cambial no período da Grande Recessão. Assim sendo, buscaremos entender o porquê dessa atuação institucionalmente fragmentada do Estado brasileiro em relação à crise.

Cumpre ainda indicar que, apesar de seu sucesso no controle e estabilização do valor do Real nos planos interno e externo, existem fundadas razões para que seja feita uma revisão

\footnotetext{
${ }^{4}$ Denominaremos políticas desse tipo como medidas de gestão de fluxos de capital, conforme têm aparecido nos documentos oficiais do Fundo Monetário Internacional desde a publicação, em 14 de novembro de 2012 , do documento Liberalization and Management of Capital Flows: An Institutional View (Disponível em < https://www.imf.org/external/np/pp/eng/2012/111412.pdf >. Acesso em 31 de maio de 2019), seguindo o documento Coherent Conclusions for the Management of Capital Flows Drawing on Country Experiences, aprovado pelo G20 Financeiro em 15 de outubro de 2011 (Disponível em < https://www.mofa.go.jp/policy/economy/g20_summit/2011/pdfs/annex05.pdf $>$. Acesso em 31 de maio de 2019).
} 
das instituições relacionadas à gestão das políticas monetária e cambial no Brasil. Entendemos que a particularidade da ação do Estado brasileiro no período se deu principalmente em razão do atual desenho institucional da gestão da moeda e do crédito no Brasil.

Por conta disso, se torna importante jogar luz sobre esse tema para que possamos estabelecer um debate que aponte um novo desenvolvimento jurídico e institucional para além do regime monetário de metas de inflação e do regime cambial de câmbio flutuante, como conhecemos e aplicamos atualmente. Compreende-se que essa discussão está longe de ser meramente institucional e em momento algum pretendemos deixar de considerar as dinâmicas materiais de disputa e apropriação do orçamento público e as condicionantes históricas existentes por trás da estruturação das normas e instituições do Estado.

A fim de cobrir essa agenda, a presente Dissertação se divide em cinco capítulos além do primeiro que contém esta introdução. Para evitar a impressão de que estaríamos tratando de algo teleológico, como uma evolução institucional rumo a uma estrutura mais racional, optamos por não seguir uma ordem necessariamente cronológica no texto. As principais questões ligadas a normas e procedimentos serão apresentadas logo após a metodologia e os conceitos e, por fim, trataremos criticamente do processo que levou as instituições de controle da moeda à conformação que possuem atualmente.

Passada esta introdução, o capítulo a seguir trata dos aspectos metodológicos e conceituais. Nele, estão expostas a metodologia simples, que desenvolvemos a partir de alguns aportes do campo das Relações Internacionais, e o desenvolvimento teórico da corrente de Direito Econômico à qual se filia o raciocínio a ser desenvolvido. Segue-se a isso, a exposição de conceitos que englobam noções econômicas e jurídicas que serão úteis para a leitura da Dissertação.

O curto terceiro capítulo, chamado as políticas monetária e cambial brasileiras antes da crise de 2008, versa sobre a institucionalidade do regime monetário de metas de inflação e do regime cambial de câmbio flutuante, que balizavam as políticas monetária e cambial brasileiras até a Grande Recessão. Procuraremos compreender suas normas e procedimentos e as instituições envolvidas.

O capítulo seguinte aborda as questões normativas e procedimentais ligadas à gestão das políticas monetária e cambial brasileiras que entendemos terem contribuído para 
a fragmentação institucional dessas políticas no período relevante deste trabalho. Para tento, esse capítulo foi dividido em três seções.

Primeiro, trataremos da reação à crise por parte das principais economias do centro do capitalismo e dos efeitos e consequências da Grande Recessão sobre as economias emergentes periféricas, especialmente na América Latina. Em seguida, apresentaremos alguns diplomas legais que o Estado brasileiro adotou para conservar o poder de compra da moeda nacional no contexto dos efeitos da Grande Recessão. Por fim, retornaremos às normas e procedimentos do regime monetário de metas de inflação e do regime cambial de câmbio flutuante, mas com um espírito crítico sobre seus fundamentos.

As questões institucionais são objeto do quinto capítulo, igualmente dividido em três seções. Começaremos com uma exposição sobre os agentes econômicos externos que historicamente exerceram alguma influência sobre as políticas monetária e cambial no Brasil. A partir daí, as seções seguintes apresentarão a evolução institucional das autoridades que detiveram competência sobre as políticas monetária e cambial no nível doméstico, sempre estabelecendo paralelos entre a atuação das instituições brasileiras e as limitações sistêmicas de maior ou menor grau. Na seção final deste capítulo, apresentamos também nossas considerações críticas sobre as instituições que atualmente detêm mandato para formulação e exercício das as políticas monetária e cambial no Brasil.

O capítulo final traz nossas conclusões. Defendemos que o controle da moeda no Brasil passe por uma revisão jurídica e institucional para além do regime de metas de inflação e do câmbio flutuante adotados em 1999. A experiência que marcou o período de 2008 a 2011 mostrou os limites do modelo atual e pode servir como marco fundamental nesse processo de revisão.

Com isso, esperamos contribuir de maneira crítica e partir do campo do Direito com as discussões sobre política monetária e política cambial que ganharam força desde a Grande Recessão e que têm sido mais usualmente conduzidas por economistas. LARA-RESENDE (2017), por exemplo, engajou-se na apresentação de novidades na teoria econômica sobre política monetária. Pontos instigantes sobre política cambial aparecem de forma relevante em ROSSI (2016) e ROSSI \& MELLO (2018). Acreditamos que o Direito possa participar desses debates. 


\section{CAPÍTULO VI - Conclusões}

\section{Acordes dissonantes}

A política monetária e a política cambial adotadas pelo Brasil entre a fase mais aguda da crise de 2008 e a passagem à Nova Matriz Econômica em agosto de 2011 tiveram características muito particulares. Do ponto de vista jurídico, chama atenção o número de instituições engajadas no enfrentamento aos efeitos negativos da Grande Recessão sobre as políticas monetária e cambial ainda que a maioria dessas instituições não tivesse um mandato legal para atuar nesse campo.

Apesar de contar com autoridades monetárias legalmente constituídas na forma do BACEN e do CMN, formalmente dotadas de competência para coordenar e exercer essas políticas, o que pôde ser visto a partir de setembro de 2008 no Brasil apontava muito mais para um conjunto fragmentado de medidas adotadas de forma ad hoc pelas instituições do governo federal para conter os efeitos negativos da Grande Recessão. Uma análise mais detida da ação do Brasil contra os efeitos da crise encontra participação do BACEN e do CMN; do BNDES; do BB; da CEF; da STN; do Ministério da Fazenda; e mesmo da Presidência da República e de um agente privado como o FGC.

Mesmo com o sucesso do País no combate à Grande Recessão, que aqui não teria sido mais que uma "marolinha" 81 , a excepcionalidade da atuação das instituições do Estado brasileiro no período não deveria passar despercebida. Diante disso, nossa preocupação foi buscar explicações com bases normativas ou institucionais para tratar desse fenômeno de fragmentação institucional, ao qual dedicamos o título deste trabalho e destas notas conclusivas.

Visando esse propósito, nossa estratégia foi analisar as normas e procedimentos de política monetária e política cambial adotadas no Brasil, bem como a conformação das instituições com mandato para exercício dessas políticas, identificando suas condicionantes históricas, econômicas e relacionadas à inserção do Brasil no sistema internacional no longo prazo. A exposição dos resultados da nossa análise se deu em duas partes, contemplando

\footnotetext{
${ }^{81}$ A expressão foi utilizada pelo Presidente Lula ainda em outubro de 2008 para minimizar os possíveis efeitos que a crise poderia ter no Brasil. A declaração foi registrada por repórteres que acompanhavam o Presidente e aparece, por exemplo, em < https://oglobo.globo.com/economia/lula-crise-tsunami-nos-eua-se-chegar-aobrasil-sera-marolinha-3827410 $>$. Acesso em 31 de maio de 2019.
} 
primeiro as limitações a que o exercício das políticas monetária e cambial pelo BACEN está exposto, por conta das normas e procedimento a que esse exercício está submetido, e, em seguida, criticamos a conformação institucional do BACEN e do CMN.

No que diz respeito a normas e procedimentos, nossa análise fez remissão à montagem do chamado "tripé" macroeconômico no Brasil, nos anos finais do Século XX. Criadas no contexto de expansão do neoliberalismo, as normas e procedimentos que derivaram desse processo serviram no momento da Grande Moderação, período de estabilidade econômica que antecedeu a crise de 2008. No entanto, durante a Grande Recessão, ficou claro que essas normas e procedimentos estavam fundamentadas sobre bases muito inconsistentes para dar conta do problema.

O CMN e o BACEN procuraram incrementar a regulação e especificamente o BACEN fez uso das ferramentas que ainda lhe restavam, ou seja, o manejo da Selic e das reservas internacionais de divisa. As limitações dos efeitos dessas políticas, entretanto, motivaram a mobilização das instituições sem mandato sobre as políticas monetária e cambial no momento da crise.

A nossa preocupação sobre a conformação institucional das autoridades monetárias brasileiras surgiu da constatação que, mesmo diante da mobilização de diferentes instituições, o órgão com mandato legal para formulação de políticas, no caso o CMN, não assumiu o papel central na coordenação da ação do Estado brasileiro. Quanto a isso, a análise histórica de mais longo prazo nos mostrou que há espaço para revisar a forma que as instituições passaram a ter após a edição da Medida Provisória no 542/1994, a fim de diversificar suas fontes de informação e dotá-las de maior capacidade de atuar em novas frentes que se abriram após a Grande Recessão, como no incremento da regulação macroprudencial. Melhor ainda se essa revisão envolver um debate aberto no espaço público, podendo-se inclusive discutir o papel outros atores institucionais como o Congresso Nacional e o COREMEC.

Para trabalhar essas questões, optamos por aplicar um modelo teórico chamado de jogo de dois níveis e a dar sempre destaque às condicionantes históricas das políticas, fossem essas condicionantes externas ou domésticas. Em momento algum deixamos de levar em consideração que as políticas monetária e cambial são resultado de um jogo que envolve interesses dentro e fora do país. 
O espaço da política doméstica na formulação das políticas monetária e cambial também marcou a história brasileira desde a controvérsia entre papelistas e metalistas no Século XIX. Sobre a atuação das forças externas, MATTLI \& WOODS (2009, p. 6), fazendo referência ao estudo de SIMMONS (2001), argumentam que a intervenção da potência hegemônica, isto é, os EUA, pode ser explícita caso uma nação integrada resolva divergir da hegemônica, em linha com a noção de que as nações, especialmente as periféricas estão sujeitas a um dilema entre abertura e autonomia:

\footnotetext{
"[Os EUA] detém uma posição que permite mudar unilateralmente o contexto dos mercados financeiros em todo o mundo. Os reguladores de outros países podem optar por emular novas regulações dos EUA ou divergir. Se a divergência é cara para os Estados Unidos, em outras palavras, é uma fonte de externalidade negativa para os Estados Unidos, então a potência hegemônica mobilizará pressão política para coagir os reguladores estrangeiros a seguir as regras dos EUA" (MATTLI \& WOODS, 2009, p. 6).
}

Outro fato que não ignoramos é que o sentido do desenvolvimento das políticas monetária e cambial e das instituições que as criam e executam não deriva de uma dinâmica natural ou racional, são fruto de política que traduz interesses em um processo histórico. Ainda que haja possibilidade de fomentar um esforço de politização maior do debate sobre o BACEN e o CMN, buscando criar um ambiente que incentive inovações institucionais e desenvolvimento de novos procedimentos e normas que venham a submeter as políticas monetária e cambial, é certo que a criação e conformação das normas e instituições atuais não são fruto do acaso, elas servem a certo interesse político que, sem dúvida, trabalhará no sentido de sua manutenção. Apesar disso acreditamos que valha a pena trazer essas normas, procedimentos e instituições para o debate e escrutínio abertos no espaço público.

Os temas econômicos, especialmente os que dizem respeito à regulação da moeda e do crédito interessam à população. Como exemplo, pode-se citar o caso recente da questão do spread bancário e o estrangulamento do crédito que já ocupou parte relevante do debate nas eleições gerais de 2018. Algumas das principais propostas presidenciais para combater esse problema envolviam desde a criação de um mecanismo tributário que levasse as instituições financeiras a reduzirem as taxas de juros ao tomador até incentivos à entrada de fintechs no mercado. A partir disso, a população foi apresentada às discussões sobre o uso de instrumentos de legislação tributária para induzir certos comportamentos desejados dos contribuintes e também relacionadas à estruturação de um sistema de operações financeiras extrabancárias mais abrangente no Brasil, especialmente observando os casos do Sudeste 
Asiático e do Caribe, onde esse tipo de arranjo e o debate sobre os desafios dele decorrentes já são mais comuns.

Depois disso, a Federação Brasileira de Bancos (FEBRABAN) já veio a público apresentar sua versão dos fatos, apresentando propostas próprias que, em sua visão, permitiriam uma diminuição nas taxas de juros ao consumidor ${ }^{82}$. A controvérsia foi, assim, trazida ao público de maneira politizada e é possível fazer o mesmo em relação a toda a matéria de regulação de moeda e crédito.

Por fim, sobre o que foi realizado de mais substancial para a melhoria da atuação do BACEN desde o segundo semestre de 2011, cumpre mencionar os esforços pelo aprimoramento da regulação do setor financeiro no Brasil, que persistiram mesmo durante o período da Nova Matriz Econômica. As recomendações dos Acordos de Basileia III contemplando os esforços de estruturação de uma regulação mais robusta passaram a compor o corpo regulatório do sistema financeiro brasileiro a partir de março de 2013, com base nas Resoluções nº 4.192 e $n^{\circ} 4.193$, ambas de $1^{\circ}$ março de 2013, e da Circular $n^{\circ} 3.644$, de 4 de março de 2013. Esses instrumentos regulatórios introduziram novos conceitos e padrões macroprudenciais para a atuação das instituições financeiras no país. ${ }^{83}$

Por mais que o incremento da regulação macroprudencial do setor financeiro seja bem-vindo, é fundamental que a ampliação do debate sobre as políticas monetária e cambial aconteça. Muito se tem falado sobre os riscos inegáveis da emergência de uma democracia iliberal (ZACARIA, 1997), mas esse fenômeno deve ser analisado ao lado de sua contraparte, o liberalismo antidemocrático (MOUNK, 2018), que exacerba a tecnocracia e a judicialização. A moeda é parte fundamental da vida de todos e suas dinâmicas políticas devem ser conhecidas e estar alinhadas aos objetivos da nossa sociedade.

\footnotetext{
${ }^{82}$ Cf. FEBRABAN (2018).

${ }^{83}$ Tratei deste tema com maior profundidade em SILVA (2018c).
} 


\section{Referências Bibliográficas}

ABREU, Marcelo de Paiva \& LAGO, Luiz Aranha Correa do. A economia brasileira no Império, 1822-1889. In. ABREU, Marcelo de Paiva (org.). A ordem do progresso. $2^{\mathrm{a}}$ ed. Rio de Janeiro: Elsevier. 2014. pp. 1-28.

AGLIETTA, Michel. The international monetary system. in. BOYER, Robert \& SAILLARD, Yves (Org.). Régulation Theory: the state of the art. Londres: Routledge. 2002. pp. 64-72.

ALMEIDA, Clóvis Oliveira de \& BACHA, Carlos José Caetano. Evolução da política cambial e da taxa de câmbio no Brasil, 1961-97. In. Pesquisa \& Debate. Vol. 10. no 2. 1999. pp. 5-29.

ARENTI, Wagner Leal \& FILOMENO, Felipe Amin. Economia política do moderno sistema mundial: as contribuições de Wallerstein, Braudel e Arrighi. In. Ensaios FEE. v. 28, n. 1. Porto Alegre: Fundação de Economia e Estatística Siegfried Emanuel Heuser. 2007.

ARRIGHI, Giovanni. O longo século XX. Rio de Janeiro: Contraponto. 2016.

ASCARELLI, Tullio. Obbligazioni Pecuniarie. Bologna: Nicola Zanichelli Editore. 1959.

ASCARELLI, Tullio. Studi giuridici sulla moneta. Milão: Dott. A. Giuffrè. 1952.

BACEN. Relatório de Inflação. Brasília: Banco Central do Brasil. v. 6. no 2. Junho de 2004.

BACEN. Relatório de Inflação. Brasília: Banco Central do Brasil. v. 10. n 4. Dezembro de 2008.

BACEN. Relatório de Inflação. Brasília: Banco Central do Brasil. v. 13. n 2. Junho de 2011.

BACEN. Relatório de Inflação. Brasília: Banco Central do Brasil. v. 17. nº 3. Setembro de 2015.

BALEEIRO, Aliomar. Uma Introdução à Ciência das Finanças. $15^{\mathrm{a}}$ ed. Rio de Janeiro: Editora Forense. 2001. 
BARBOSA-FILHO, Nelson. Brazil's Political Challenge: Building Consensus on an Economically Sustainable Strategy. Wilson Center - Brazil Institute Special Report: Washington D.C. 2013.

BARBOSA-FILHO, Nelson. Inflation targeting in Brazil: 1999-2006. International Review of Applied Economics, v. 25, n. 2. 2008. pp. 127-148.

BASTOS, Estêvão Kopschitz Xavier, \& FONTES, Patrícia Vivas da Silva. Mercado de câmbio brasileiro, intervenções do Banco Central e controles de capitais de 1999 a 2012. Texto para discussão no 1934. Brasília: IPEA. Fevereiro de 2014.

BELLUZZO, Luiz Gonzaga. Finança global e ciclos de expansão. In. FIORI, José Luís da Costa (Org.). Estados e moedas no desenvolvimento das nações. $4^{\mathrm{a}}$ ed. Petrópolis: Editora Vozes. 2012b. pp. 87-117.

BELLUZZO, Luiz Gonzaga. O capital e suas metamorfoses. São Paulo: UNESP. 2012a.

BERCOVICI, Gilberto \& MASSONETTO, Luís Fernando. A Constituição Dirigente Invertida: a Blindagem da Constituição Financeira e a Agonia da Constituição Econômica. Boletim de Ciências Económicas (Coimbra), v. XLIX, p. 1-23, 2006.

BERCOVICI, Gilberto \& MASSONETTO, Luís Fernando. Limites da Regulação: Esboço para uma Crítica Metodológica do "Novo Direito Público da Economia". Revista de Direito Público da Economia. v. 25. 2009. pp. 137-147.

BERCOVICI, Gilberto. O Ainda Indispensável Direito Econômico. In. BENEVIDES, Maria Victoria de Mesquita; BERCOVICI, Gilberto \& MELO, Claudineu de (orgs.), Direitos Humanos, Democracia e República: Homenagem a Fábio Konder Comparato. São Paulo: Quartier Latin. 2009. pp. 503-519.

BERCOVICI, Gilberto. Política Econômica e Direito Econômico. Revista Fórum de Direito Econômico e Financeiro, v. 1, p. 199-219, 2012.

BERNANKE, Ben S. \& MIHOV, Ilian. Measuring Monetary Policy. In. The Quarterly Journal of Economics. Vol. 113. No 3. Agosto de 1998. pp. 869-902.

BERNANKE, Ben S. \& MISHKIN, Frederic S. Inflation Targeting: A New Framework for Monetary Policy? In. The Journal of Economic Perspectives. Vol. 11. no 2. Nashville: American Economic Association. 1997. pp. 97-116.

BIELSCHOWSKY, Ricardo (Org.). Cinquenta anos de pensamento na CEPAL. Vol. 1. Rio de Janeiro: Record. 2000. 
BIELSCHOWSKY, Ricardo (Org.). Cinquenta anos de pensamento na CEPAL. Vol. 2. Rio de Janeiro: Record. 2000.

BLANCHARD, Olivier. Rewriting the Macroeconomists' Playbook in the Wake of the Crisis. Março de 2011. Disponível em < https://blogs.imf.org/2011/03/04/2662/ >. Acesso em 31 de maio de 2019.

BLANCHARD, Olivier; DELL'ARICCIA, Giovanni \& MAURO, Paolo. Rethinking Macroeconomic Policy. IMF staff position note. Nova Iorque: Fundo Monetário Internacional. 12 de fevereiro de 2010.

BORIO, Claudio. Central banking post-crisis: what compass for uncharted waters? BIS Working Paper 353. Basileia: Bank for International Settlements. 2011.

BOYER, Robert \& SAILLARD, Yves. A summary of régulation theory in. BOYER, Robert \& SAILLARD, Yves (Org.). Régulation Theory: the state of the art. Londres: Routledge. 2002. pp. 36-44.

BOYER, Robert. The origins of régulation theory. in. BOYER, Robert \& SAILLARD, Yves (Org.). Régulation Theory: the state of the art. Londres: Routledge. 2002. pp. 13-20.

BOYER, Robert. Teoria da Regulação: os fundamentos. São Paulo: Estação Liberdade. 2009.

BRESSER-PEREIRA, Luiz Carlos. A descoberta da inflação inercial. In. Revista de economia contemporânea. vol.14. n.1. 2010. pp. 167-192.

BRITO, Márcio Holland de. Taxa de câmbio e regimes cambiais no Brasil. Tese de Doutorado. Instituto de Economia. Universidade Estadual de Campinas. Campinas. 1998.

BROADBERRY, Stephen \& O'ROURKE, Kevin. The Cambridge Economic History of Modern Europe: Volume 2, 1870 to the present. Cambridge: Cambridge University Press. 2010.

BROOKS, Sarah M., CUNHA, Raphael \& MOSLEY, Layna. Categories, Creditworthiness, and Contagion: How Investors' Shortcuts Affect Sovereign Debt Markets. International Studies Quarterly. Vol. 59. n. 3. 2015. 
CAMARA, Mamadou, \& SALAMA, Pierre. A inserção diferenciada - com efeitos paradoxais - dos países em desenvolvimento na mundialização financeira. in. CHESNAIS, François. A Finança Mundializada. São Paulo: Boitempo. 2005. pp. 199-221.

CAMPEDELLI, André Luis. O regime de metas de inflação: uma crítica a partir da visão heterodoxa. In. LACERDA, Antonio Corrêa de (Org.). Desenvolvimento brasileiro em debate. São Paulo: Blucher. 2017. pp. 49-77.

CANUTO, Otaviano \& CAVALLARI, Matheus. Monetary Policy and Macro Prudential Regulation: Whither Emerging Markets. In. CANUTO, Otaviano \& GHOSH, Swati R. (orgs.). Dealing with the challenges of macro financial linkages in emerging markets. Economic premise $\mathrm{N}^{\circ} 129$. Washington DC: Banco Mundial. 2013. pp. 119-154.

CARNEIRO, Dionísio Dias \& MODIANO, Eduardo Marco. Ajuste externo e desequilíbrio interno, 1980-1984. In. ABREU, Marcelo de Paiva (org.). A ordem do progresso. $2^{\mathrm{a}}$ ed. Rio de Janeiro: Elsevier. 2014. pp. 263-280.

CARVALHO, Fabia A. \& CASTRO, Marcos R. de. Macroprudential and Monetary Policy Interaction: a Brazilian perspective. Working paper $\mathrm{n}^{\circ} 405$. Brasília: Banco Central do Brasil. Novembro de 2015.

CARVALHO, Fabia A. \& MINELlA, André. Previsões de Mercado no Brasil: desempenho e determinantes. In. BACEN. Dez Anos de Metas para a Inflação 1999-2009. Brasília: Banco Central do Brasil. 2011. pp. 169-226.

CARVALHO, José Carlos. Economias maduras e a prescrição da irresponsabilidade monetária e fiscal como modo de vida. In. BACHA, Edmar (org.). A crise fiscal e monetária brasileira. $2^{a}$ ed. Rio de Janeiro: Civilização brasileira. 2017. pp. 507-524.

CARVALHO, Laura Barbosa de, \& RUGITSKY, Fernando. Growth and distribution in Brazil in the 21st century: revisiting the wage-led versus profit-led debate. Working Paper series. $n^{\circ}$ 2015-25. Departamento de Economia da FEA-USP.

CARVALHO, Laura Barbosa de. Valsa brasileira. São Paulo: Todavia. 2018.

CASTRO, Marcos R. de; GOUVEA, Solange N.; MINELLA, André; SANTOS, Rafael C. \& SOUZA-SOBRINHO, Nelson F. SAMBA: Stochastic Analytical Model with a Bayesian Approach. Working paper series. N ${ }^{\circ}$ 239. Brasília: Banco Central do Brasil. Abril de 2011. 
CHACHAMOVITZ, Solange Srour. Reservas internacionais: seguro ou ameaça? In. BACHA, Edmar (org.). A crise fiscal e monetária brasileira. $2^{\mathrm{a}}$ ed. Rio de Janeiro: Civilização brasileira. 2017. pp. 347-356.

CHESNAIS, François. Introdução geral. in. CHESNAIS, François. A Mundialização Financeira. São Paulo: Xamã. 1999. pp. 11-33.

CHESNAIS, François. O capital portador de juros: acumulação, internacionalização, efeitos econômicos e políticos. in. CHESNAIS, François. A Finança Mundializada, São Paulo: Boitempo. 2005. pp. 35-67.

CINTRA, Marcos Antonio Macedo. Suave fracasso: a política macroeconômica brasileira entre 1999 e 2005. In. Novos estudos. n. 73. São Paulo: CEBRAP. 2005. pp. 39-56.

CLARK, William Robert \& HALLERBERG, Mark. Mobile Capital, Domestic Institutions and Electorally Induced Monetary and Fiscal Policy. In. American Political Science Review. No 94. June de 2000. pp. 323-346.

CLARK, William Robert; GOLER, Sona \& POAST, Paul. Monetary Institutions and the Political Survival of Democratic Leaders. In. International Studies Quarterly. Vol. 57. Setembro de 2013. pp 556-567.

CLAVIN, Patricia \& WESSELS, Jens-Wilhelm. Another Golden Idol? The League of Nations' Gold Delegation and the Great Depression, 1929-1932. In. The International History Review. Vol. 26. n. 4. Abingdon-on-Thames: Taylor \& Francis. 2004. pp. 765-795.

CLEMENT, Piet. The term “macroprudential”: origins and evolution. In. BIS Quarterly Review, Março de 2010. pp. 59-67.

COMPARATO, Fábio Konder. O Indispensável Direito Econômico. In. Ensaios e Pareceres de Direito Empresarial. Rio de Janeiro: Forense. 1978. pp. 453-472.

CONCEIÇÃO TAVARES, Maria da \& FIORI, José Luís da Costa (Orgs.). Poder e Dinheiro: Uma Economia Política da Globalização. $5^{\mathrm{a}}$ ed. Petrópolis: Editora Vozes. 1998.

CONCEIÇÃO TAVARES, Maria da. Império, território e dinheiro. In. FIORI, José Luís da Costa (Org.). Estados e moedas no desenvolvimento das nações. $4^{\mathrm{a}} \mathrm{ed}$. Petrópolis: Editora Vozes. 2012. pp. 449-489. 
CONCEIÇÃO-HELDT, Eugénia \& MELLO, Patrick A. Two-Level Games in Foreign Policy Analysis. In. Oxford Research Encyclopedia of Politics. Nova Iorque \& Oxford: Oxford University Press. 2017.

COSTA, Luciana Pereira. Disciplina jurídica do câmbio e política pública. 2009. Dissertação de Mestrado. Faculdade de Direito. Universidade de São Paulo. São Paulo. 2009.

COZER, Cristiano de Oliveira Lopes. Natureza e propriedades da moeda: contribuição para o estudo do Direito monetário no Brasil. Tese de Doutorado. Faculdade de Direito. Universidade de Brasília. 2006.

CVM. Mercado de Valores Mobiliários Brasileiro. $3^{\mathrm{a}}$ ed. TOP - Programa de treinamento de professores. Rio de Janeiro: Comissão de Valores Mobiliários. 2014.

DE BOLLE, Monica Baumgarten. Como matar a borboleta-azul: uma crônica da era Dilma. Rio de Janeiro: Intrínseca. 2016.

DE CHIARA, José Tadeu. Moeda e ordem jurídica. Tese de Doutorado. Faculdade de Direito. Universidade de São Paulo. São Paulo. 1986.

DINIZ, André; CARVALHO, Laura Barbosa de; MARTINS, Ítalo \& ROSSI, Pedro. Custos fiscais da política monetária: os efeitos indiretos de um choque de juros sobre a dívida líquida do setor público. Anais do XLI Encontro Nacional de Economia da ANPEC. 2014.

DOWBOR, Ladislau. A era do capital improdutivo: Por que oito famílias têm mais riqueza do que a metade da população do mundo? São Paulo: Autonomia Literária. 2017.

DURAN, Camila Villard \& BORGES, Caio. Enfrentando a crise financeira: como constrangimentos jurídicos causaram afragmentação institucional do poder monetário brasileiro no pós-2008. In. Revista Direito GV. Vol. 14. no 2. São Paulo: Escola de Direito de São Paulo - Fundação Getúlio Vargas. 2018. pp. 450-491.

DURAN, Camila Villard. A moldura jurídica da política monetária: um estudo de caso. Tese de Doutorado. FDUSP. 2012.

DURAN, Camila Villard. Monetary policy: making fragmentation work. In: Tom HALE, Tom \& HELD, David (Org.). Beyond gridlock. Cambridge: Polity. 2017. pp. 48-64. 
EICHENGREEN, Barry. A globalização do capital. São Paulo: Editora 34. 2012.

EICHENGREEN, Barry. International Policy Coordination: The Long View. In. FEENSTRA, Robert C. \& TAYLOR, Alan M. (eds.). Globalization in an Age of Crisis: Multilateral Economic Cooperation in the Twenty-First Century. Chicago: University of Chicago Press. 2013. pp. 43-82.

EICHENGREEN, Barry; EL-ERIAN, Mohamed; FRAGA NETO, Armínio; ITO, Takatoshi; PISIANI-FERRY, Jean; PRASAD, Eswar; RAJAN, Raghuram; RAMOS, Maria; REINHART, Carmen; REY, Hélène; RODRIK, Dani; ROGOFF, Kenneth; SHIN, Hyun Song; VELASCO, Andrés; DI MAURO, Beatrice Weder; \& YU, Yongding. Rethinking Central Banking - The Committee on International Economic and Policy Reform. Brookings Institutions: Washington, D.C. 2011.

FARHI, Maryse. Crise financeira e reformas da supervisão e regulação. Texto para discussão nº 1581. Brasília: IPEA. Fevereiro de 2011.

FEBRABAN. Como fazer os juros serem mais baixos no Brasil: Uma proposta dos bancos ao governo, Congresso, Judiciário e sociedade. Federação Brasileira de Bancos: São Paulo. 2018.

FECOMERCIO. Índices de preços no Brasil: Um estudo sobre o Índice de Preços ao Consumidor da Fundação Instituto de Pesquisas Econômicas: IPCA-IBGE. Cadernos Fecomercio de Economia. n. 6. São Paulo: Federação do Comércio do Estado de São Paulo. 2005.

FERNANDES, Felipe Tâmega. Bancos Centrais e Tesouros sob políticas monetárias experimentais. In. BACHA, Edmar (org.). A crise fiscal e monetária brasileira. $2^{\mathrm{a}}$ ed. Rio de Janeiro: Civilização brasileira. 2017. pp. 525-548.

FIESP, CUT, SINDICATO DOS METALÚRGICOS DO ABC, FORÇA SINDICAL \& SINDICATO DOS METALÚRGICOS DE SÃO PAULO E MOGI DAS CRUZES. Brasil do diálogo, da produção e do emprego. São Paulo: Federação da Indústrias do Estado de São Paulo; Central Única dos Trabalhadores; Sindicato dos Metalúrgicos do ABC; Força Sindical; e Sindicato dos Metalúrgicos de São Paulo e Mogi das Cruzes. 2011.

FIGUEIREDO, Francisco Marcos Rodrigues \& GOUVEA, Solange. Repasse Cambial para a Inflação: o papel da rigidez de preços. In. BACEN. Dez Anos de Metas para a Inflação - 1999-2009. Brasília: Banco Central do Brasil. 2011. pp. 127168. 
FILGUEIRAS, Luiz. A história do Plano Real. São Paulo: Boitempo. 2000.

FLEMING, J. Marcus. Domestic financial policies under fixed and floating exchange rates. In. IMF Staff Papers. N. 9. 1962. pp. 369-379.

FONSECA, Pedro Cezar Dutra. A Controvérsia entre Metalismo e Papelismo e a Gênese do Desenvolvimentismo no Brasil. In: XXXVI Encontro Nacional de Economia da ANPEC, 2008, Salvador, BA. Anais do XXXVI Encontro Nacional da ANPEC - v.CDRom, 2008.

FOURASTIÉ, Jean. Les Trente Glorieuses, ou la révolution invisible de 1946 à 1975. Paris: Fayard. 1979.

FRANCO, Gustavo Henrique de Barroso. A moeda e a lei: uma história monetária brasileira (1933-2013). Rio de Janeiro: Zahar. 2017 b.

FRANCO, Gustavo Henrique de Barroso. A primeira década republicana. In. ABREU, Marcelo de Paiva (org.). A ordem do progresso. $2^{\mathrm{a}}$ ed. Rio de Janeiro: Elsevier. 2014. pp. 29-44.

FRANCO, Gustavo Henrique de Barroso. Auge e declínio do inflacionismo no Brasil. Texto para discussão no departamento de economia da PUC-RJ. Rio de Janeiro: Pontifícia Universidade Católica. Set. 2004.

FRANCO, Gustavo Henrique de Barroso. O Conselho Monetário Nacional como autoridade monetária: das origens aos dias atuais. In. BACHA, Edmar (org.). A crise fiscal e monetária brasileira. $2^{\mathrm{a}}$ ed. Rio de Janeiro: Civilização brasileira. 2017a. pp. 39-66.

FRANKEL, Jeffrey Alexander. What's In and Out in Global Money. In. Finance and Development. v. 46. n. 3. Washington, DC: FMI. 2009. pp. 13-17.

FRANZESE, Robert. Partially Independent Central Banks, Politically Responsive Governments, and Inflation. American Journal of Political Science. Vol. 43. n. 3. 1999. pp. 681-706.

FREITAS, Maria Cristina Penido de. Os efeitos da crise global no Brasil: aversão ao risco e preferência pela liquidez no mercado de crédito. In. Estudos Avançados. v. 23. nº 66. São Paulo: IEA/USP. 2009. pp. 125-145.

FRIEDEN, Jeffry, S.; BLOMBERG, Brock \& STEIN, Ernesto. Sustaining Fixed Exchange Rates: The Political Economy of Currency Pegs in Latin America. In. Journal of Applied Economics. Vol. 8. n 2. 2005. 203-225. 
FRIEDMAN, Milton. The Quantity Theory of Money - A Restatement. In. Studies in the Quantity Theory of Money. Chicago: University of Chicago Press. 1956. pp. $3-21$.

FRIEDMAN, Milton. The Role of Monetary Policy. in. The American Economic Review. Vol. 58. n. 1. Março de 1968. pp. 1-17.

FURTADO, Celso. Formação econômica do Brasil. 27 ed. São Paulo: Companhia Editora Nacional/Publifolha. 2000.

GALLO, Ricardo Augusto. Banco Central e Tesouro: conjecturas sobre as consequências práticas de um relacionamento íntimo. In. BACHA, Edmar (org.). A crise fiscal e monetária brasileira. $2^{\mathrm{a}}$ ed. Rio de Janeiro: Civilização brasileira. 2017. pp. 271-293.

GIAMBIAGI, Fabio; VILLELA, André; BARROS DE CASTRO, Lavinia \& HERMANN, Jennifer (orgs.). Economia brasileira contemporânea: 1945-2010. $2^{\mathrm{a}}$ ed. Rio de Janeiro: Elsevier. 2011.

GOLDFAJN, Ilan. Comitê de Política Cambial para as reservas do Banco Central: uma proposta. In. BACHA, Edmar (org.). A crise fiscal e monetária brasileira. $2^{\mathrm{a}} \mathrm{ed}$. Rio de Janeiro: Civilização brasileira. 2017. pp. 357-369.

GOMES, Cleomar \& HOLLAND, Márcio. Regra de Taylor e política monetária em condições de endividamento público no Brasil. In. Revista Economia. v. 4. n. 2. Niteroi: ANPEC. 2003. pp. 333-359.

GOUREVITCH, Peter. The Second Image Reversed: The International Sources of Domestic Politics. In. International Organization. Vol. 32. $\mathrm{n}^{\mathrm{o}}$ 4. Madison: University of Wisconsin Press. 1978. pp. 881-912.

GRAY, Joanna. Behavioural finance and the macroprudential dimension. In. Journal of Banking Regulation. Vol. 17. N 4. Novembro de 2016. pp 296-310.

GRAY, Joanna. What is Systemic Risk and what can be done about it? A Legal Perspective. Florença: Robert Schuman Centre for Advanced Studies - European University Institute. 2011.

GREMAUD, Amaury Patrick; BRAGA, Márcio Bobik, \& VASCONCELLOS, Marco Antonio Sandoval de. A Macroeconomia do Setor Externo: Uma Introdução. No prelo. 
GUDIN, Eugênio. Princípios de economia monetária. Vol. 1. Rio de Janeiro: Civilização Brasileira. 1943.

HALEY, Mary Ann. Emerging Market Makers: The Power of Institutional Investors. In. ARMIJO, Leslie Ann (Ed.). Financial Globalization and Democracy in Emerging Markets. Nova York: St. Martin's Press. 1999. pp. 74-89

HARVEY, David. A brief history of neoliberalism. Oxford: Oxford University Press. 2009.

HEGEL, Georg Wilhelm Friedrich. Princípios da filosofia do direito. São Paulo: Martins Fontes. 1997.

HENDRY, David \& MIZON, Grayham. Why DSGEs crash during crises. Junho de 2014. Disponível em < https://voxeu.org/article/why-standard-macro-modelsfail-crises $>$. Acesso em 31 de maio de 2019.

HICKS, John. Mr. Keynes and the "Classics": A Suggested Interpretation. in. Econometrica. Vol. 5. n. 2. 1937. pp. 147-159.

IPEA. Banco do Brasil, BNDES e Caixa Econômica Federal: a atuação dos bancos públicos federais no período 2003-2010. Comunicado nº 105. 2011.

JALORETTO, Cláudio. Banco Central do Brasil: evolução histórica e questões atuais. In. BACHA, Edmar (org.). A crise fiscal e monetária brasileira. $2^{\mathrm{a}}$ ed. Rio de Janeiro: Civilização brasileira. 2017. pp. 67-85.

JHERING, Rudolf von. A Evolução do Direito. $2^{\mathrm{a}}$ ed. Salvador: Livraria Progresso Editora. 1956.

JINJARAK, Yothin; NOY, Ilan \& ZHENG, Huanhuan. How effective were the 20082011 capital controls in Brazil? Novembro de 2012. Disponível em < https://voxeu.org/article/how-effective-were-2008-2011-capital-controls-brazil

$>$. Acesso em 31 de maio de 2019.

JOYCE, Michael; TONG, Matthew \& WOODS, Robert. The United Kingdom's Quantitative Easing Policy: Design, Operation and Impact. In. Bank of England Quarterly Bulletin. 19 de Setembro de 2011.pp. 200-212.

KAPLAN Stephen B., \& THOMSSON, Kaj. The Political Economy of Sovereign Debt: Global Finance and Electoral Cycles. In. The Journal of Politics. Vol. 79. No 2. 2017. pp. 625-623. 
KEYNES, John Maynard. Teoria Geral do emprego, do juro e da moeda. São Paulo: Saraiva. 2012.

KEYNES, John Maynard. The economic consequences of the peace. Londres: Macmillan. 1919.

KNAPP, Georg Friedrich. The state theory of money. Londres: Macmillan and Co. 1924.

KOWARICK, Lúcio. Trabalho e vadiagem: A origem do trabalho livre no Brasil. $2^{\mathrm{a}}$ Edição. Rio de Janeiro: Editora Paz e Terra. 1994.

LARA RESENDE, André, \& ARIDA, Pérsio. Inertial inflation and monetary reform in Brazil. Rio de Janeiro: Departamento de Economia - PUC/RJ. 1985.

LARA RESENDE, André. Juros, moeda e ortodoxia. São Paulo: Portfolio Penguin. 2017.

LIM, Daniel Yew Mao \& VREELAND, James Raymond (2013). Regional Organizations and International Politics: Japanese Influence over the Asian Development Bank and the UN Security Council. In. World Politics 65 (1) pp. 34-72.

LOPES, Francisco Lafaiete. Só um Choque Heterodoxo pode Derrubar a Inflação. in. Economia em Perspectiva. n. ${ }^{\circ}$ 5. São Paulo: CORECON. Agosto de 1984. pp. 13.

LUCAS, Robert \& SARGENT, Thomas. After Keynesian Macroeconomics. In. Quarterly Review. v. 3. n. 2. Minneapolis: Federal Reserve Bank of Minneapolis. 1979. pp. 1-16.

LUCAS, Robert. Macroeconomic Priorities. In. American Economic Review, v. 93. 2003. pp 1-14.

MACDOUGALL-SHACKLETON, Scott A. The levels of analysis revisited. In: Philosophical Transactions: Biological Sciences. Vol. 366, No 1574. 2011. pp. 2076-2085.

MANKIW, N. Gregory. Introdução à Economia. Tradução da $5^{\text {a }}$ edição norteamericana. São Paulo: Cengage Learning. 2012. 
MARCUSSEN, Martin. Scientization of central banking: the politics of apoliticization. In: MARCUSSEN, Martin \& DYSON, Kenneth (Org.). Central banks in the age of the euro: Europeanization, convergence and Power. Oxford: Oxford University Press, 2009.

MARTINS, Alexandre Marques da Silva. Os valores em Miguel Reale. In. Revista de Informação Legislativa. Brasília: Senado Federal. Vol. 45. № 180. Dezembro de 2008.

MARX, Karl. O Capital. Livro III. São Paulo: Boitempo, 2017.

MASSONETTO, Luís Fernando. O direito financeiro no capitalismo contemporâneo: a emergência de um novo padrão normativo. Tese de Doutorado. Faculdade de Direito. Universidade de São Paulo. São Paulo. 2006.

MATTLI, Walter \& WOODS, Ngaire (orgs.). The Politics of Global Regulation. Princeton: Princeton University. 2009.

MATTOS FILHO, Ary Oswaldo \& PRADO, Viviane Muller. Tentativas de desenvolvimento do mercado acionário brasileiro desde 1964. In. LIMA, Maria Lúcia Labate Mantovanini Pádua (org.). Direito e economia: 30 anos de Brasil. Tomo 2. Saraiva: São Paulo. 2011.

MESQUITA, Mário \& TORÓS, Mario. Considerações sobre a atuação do Banco Central na crise de 2008. Texto para Discussão. nº 202. Brasília: Banco Central do Brasil, 2010.

MESQUITA, Mário. Inflação, estagnação e ruptura, 1961-1964. In. ABREU, Marcelo de Paiva (org.). A ordem do progresso. $2^{\mathrm{a}}$ ed. Rio de Janeiro: Elsevier. 2014. pp. 179-196.

MINELLA, André \& SOUZA-SOBRINHO, Nelson Ferreira. Canais Monetários no Brasil sob a Ótica de um Modelo Semiestrutural. In. BACEN. Dez Anos de Metas para a Inflação - 1999-2009. Brasília: Banco Central do Brasil. 2011. pp. 35-93.

MODENESI, André de Melo. Regimes monetários: teoria e a experiência do Real. Barueri: Manole. 2005.

MODIANO, Eduardo Marco. A ópera dos três cruzados, 1985-1990. In. ABREU, Marcelo de Paiva (org.). A ordem do progresso. $2^{\mathrm{a}}$ ed. Rio de Janeiro: Elsevier. 2014. pp. 281-312. 
MOREIRA, Vital. Auto-regulação profissional e Administração Pública. Coimbra: Livraria Almedina. 1997.

MORIN, François. L'hydre mondiale : L'oligopole bancaire. Montreal: Lux. 2015.

MOSLEY, Layna. Global Capital and national governments. Nova Iorque: Cambridge University Press. 2003.

MOSQUERA, Roberto Quiroga. Direito Monetário e Tributação da Moeda. São Paulo: Dialética. 2006.

MOUNK, Yascha. The People vs. Democracy. Cambridge: Harvard University Press. 2018.

MOURA, Maurício Costa de, \& BANDEIRA, Fernanda Martins. Macroprudential policy in Brazil. BIS Paper $n^{\circ}$ 94. Basileia: Bank for International Settlements. 2017. pp. 77-86.

MUNDELL, Robert. Capital Mobility and Stabilization Policy under Fixed and Flexible Exchange Rates. In. The Canadian Journal of Economics and Political Science / Revue canadienne d'Economique et de Science politique. V. 29. N. 4 Nov. 1963. pp. 475-485.

MUNHOZ, Vanessa da Costa Val. Vulnerabilidade externa e controle de capitais no Brasil: uma análise das inter-relações entre câmbio, fluxos de capitais, IOF, juros e risco-país. In. Nova economia. Vol. 23, nº 2. Belo Horizonte: UFMG. 2013. pp. 371-402.

NUSSBAUM, Arthur. Teoria Jurídica del Dinero. Madri: Librería General de Victoriano Suárez, 1929.

OBSTFELD, Maurice. The International Monetary System: Living with Asymmetry. In. FEENSTRA, Robert C. \& TAYLOR, Alan M. (eds.). Globalization in an Age of Crisis: Multilateral Economic Cooperation in the Twenty-First Century. Chicago: University of Chicago Press. 2013. pp. 301-336.

OCTAVIANI, Alessandro. O ordenamento da inovação: a economia política da forma jurídica. São Paulo. 2010. Disponível em < http://docplayer.com.br/7072877-Oordenamento-da-inovacao-a-economia-politica-da-forma-juridica.html >. Acesso em 31 de maio de 2019. 
OLIVEIRA, Luís Maurício Sodré de. Mercado de câmbio: contribuição ao disciplinamento jurídico no Brasil. Curitiba: Juruá. 2009.

OSTRY, Jonathan; LOUNGANI, Prakash, \& FURCERI, Davide. Neoliberalism: Oversold? In: Finance \& Development. Vol. 53. $\mathrm{n}^{\mathrm{o}}$ 2. Nova Iorque: Fundo Monetário Internacional. Junho de 2016. pp. 38-41.

PAIM, Paulo. Salário Mínimo uma história de luta. Brasília: Senado Federal. 2005.

PASSARI, Evgenia \& REY, Hélène. Financial Flows and the International Monetary System. In. The Economic Journal N. 125. Maio de 2015. pp. 675-698.

PASTORE, Affonso Celso \& PINOTTI, Maria Cristina. Inflação e estabilização: Algumas lições da experiência brasileira. São Paulo: A.C. Pastore \& Associados S/C Ltda. Novembro de 1997.

PASTORE, Affonso Celso. Desajuste fiscal e inflação: uma perspectiva histórica. In. BACHA, Edmar (org.). A crise fiscal e monetária brasileira. $2^{\mathrm{a}}$ ed. Rio de Janeiro: Civilização brasileira. 2017. pp. 431-448.

PECEQUILO, Cristina Soreanu. Manual do Candidato - Política Internacional. Brasília: FUNAG. 2012.

PELÁEZ, Carlos Manuel \& SUZIGAN, Wilson. História monetária do Brasil, $2^{\mathrm{a}}$ ed. Brasília: Editora Universidade de Brasília. 1995.

PHILLIPS, Alban William. The Relation between Unemployment and the Rate of Change of Money Wage Rates in the United Kingdom, 1861-1957. in. Economica New Series. Vol. 25. n. 100. Novembro de 1958. pp. 283-299.

PIKETTY, Thomas. O capital no Século XXI. Rio de Janeiro: Intrínseca. 2014.

PINHO NETO, Demosthenes Madureira de. O interregno Café Filho, 1954-1955. In. ABREU, Marcelo de Paiva (org.). A ordem do progresso. $2^{\mathrm{a}}$ ed. Rio de Janeiro: Elsevier. 2014. pp. 143-156.

PISTOR, Katharina. A Legal Theory of Finance. in. Journal of Comparative Economics. Vol. 41, No. 2. 2013. pp. 311-330.

POLANYI, Karl. A grande transformação: as origens políticas e econômicas do nosso tempo. 2a ed., Rio de Janeiro: Campus. 2012. 
PORTUGUÊS, Míriam Oliveira Silva. Recolhimento compulsório como instrumento macroprudencial no Brasil e na Colômbia: algumas evidências empíricas. Dissertação de Mestrado. Instituto de Economia. Universidade Federal do Rio de Janeiro. Rio de Janeiro. 2013.

POSNER, Eric A. Last Resort: The Financial Crisis and the Future of Bailouts. Chicago: University of Chicago Press. 2018.

PRADO JÚNIOR, Caio. Evolução Política do Brasil. São Paulo: Brasiliense. 1999.

PRADO JÚNIOR, Caio. História Econômica do Brasil. $31^{\text {a }}$ ed. São Paulo: Brasiliense. 1985.

PRÉBISCH, Raul. O desenvolvimento econômico da América Latina e alguns de seus problemas principais. in. BIELSCHOWSKY, Ricardo (Org.). Cinquenta anos de pensamento na CEPAL. Vol. 1. Rio de Janeiro: Record. 2000. pp. 70-136.

PRZEWORSKI, Adam \& VREELAND, James Raymond. (2000). The Effect of IMF Programs on Economic Growth. Journal of Development Economics. Vol. 62. n. 2. 2000. pp. 385-421.

PUTNAM, Robert. (1988). Diplomacy and Domestic Politics: The Logic of Two-Level Games. In. International Organization. Vol. 42, No 3. Verão 1988. pp. 427-460.

REALE, Miguel. Lições preliminares de Direito. $25^{\mathrm{a}}$ ed. $22^{\mathrm{a}}$ tir. São Paulo: Saraiva. 2001.

REY, Hélène. Dilemma not Trilemma: The Global Financial Cycle and Monetary Policy Independence. NBER Working Paper N. 21162. 2015a.

REY, Hélène. International Channels of Transmission of Monetary Policy and the Mundellian Trilemma. Mundell Fleming Lecture. 2015b.

RICARDO, David. Princípios da Economia Política e Tributação. Coleção $O s$ Economistas. São Paulo: Nova cultura. 1996.

RODRIK, Dani. The social cost of foreign Exchange reserves. NBER Working Paper $\mathrm{N}^{\mathrm{o}}$ 11952. Janeiro de 2006.

ROLFE, Sydney \& BURTLE, James. O Sistema monetário mundial: uma reinterpretação. Rio de Janeiro: Zahar. 1975. 
ROMER, Paul. The trouble with macroeconomics. Nova Iorque: New York University. Setembro de 2016.

ROSSI, Pedro \& MELLO, Guilherme. Do industrialismo à austeridade: a política macro dos governos Dilma. In. CARNEIRO, Ricardo; BALTAR, Paulo \& SARTI, Fernando. Para além da política econômica. São Paulo: Editora Unesp Digital. 2018.

ROSSI, Pedro. Taxa de câmbio e política cambial no Brasil: Teoria, institucionalidade, papel da arbitragem e especulação. Rio de Janeiro: FGV. 2016.

SABBAG, Eduardo de Moraes. Elementos do Direito: Direito Tributário. $3^{a}$ ed. São Paulo: Siciliano Jurídico. 2003.

SANDOVAL, Salvador. Os trabalhadores param: Greves e mudança social no Brasil 1945-1990. São Paulo: Ática. 1994.

SANTANA, Marco Aurélio. Trabalhadores em movimento: o sindicalismo brasileiro nos anos 1980-1990. In. FERREIRA, Jorge \& DELGADO, Lucilia de Almeida Neves (Orgs.). O Brasil republicano. v.4. Rio de Janeiro: Civilização Brasileira. 2003. pp. 283-313.

SANTIAGO, Saulo Quadros. A vulnerabilidade externa brasileira no regime cambial de flutuação suja. Texto para discussão nº 2321. Brasília: IPEA. Agosto de 2017.

SAWAYA, Rubens. Ortodoxia e desenvolvimento: inflação e mito. In. LACERDA, Antonio Corrêa de (Org.). Desenvolvimento brasileiro em debate. São Paulo: Blucher. 2017. pp. 49-77.

SAYAD, João. Dinheiro, Dinheiro. São Paulo: Portfolio/Penguin. 2015.

SCHWARTSMAN, Alexandre. Metas para a inflação: imperfeitas para um mundo imperfeito. in. URANI, André, GIAMBIAGI, Fabio \& REIS, José Guilherme (Org.). Reformas no Brasil: Balanço e agenda. Rio de Janeiro: Nova Fronteira. 2004.

SENADO FEDERAL. Relatório de acompanhamento fiscal. Brasília: Instituição Fiscal Independente. Junho de 2017.

SILVA, Anderson Caputo. Origem e história da dívida pública no Brasil até 1963. In. SILVA, Anderson Caputo; CARVALHO, Lena Oliveira de \& MEDEIROS, Otavio Ladeira de (orgs.). Dívida pública: a experiência brasileira. Brasília: STN. 2009. pp. 33-56. 
SILVA, Gustavo Jorge. "Desesperadamente otimistas" no FMI e Banco Mundial. 2018a. Disponível em $<$ https://outraspalavras.net/desigualdadesmundo/desesperadamente-otimistas-no-fmi-e-banco-mundial/ $>$. Acesso em 31 de maio de 2019.

SILVA, Gustavo Jorge. A demanda por crédito pela cafeicultura no Segundo Reinado: paralelos entre hipoteca de escravos e de terras no século XIX. Revista Fórum de Direito Financeiro e Econômico - RFDFE. Vol. 12. 2018b. pp. 125-145.

SILVA, Gustavo Jorge. Crise e regulação macroprudencial no Brasil: Efeitos da Grande Recessão sobre a estrutura regulatória das instituições financeiras brasileiras. 2018c. Disponível em https://drive.google.com/file/d/1vV2u1L1vpME0NU41Xa6hSDbuyGxcLa_view >. Acesso em 31 de maio de 2019.

SILVA, Gustavo Jorge. O Tripé Macroeconômico: O que é e de onde vem? 2016. Disponível em < https://www.politize.com.br/tripe-macroeconomico-o-que-e/ > . Acesso em 31 de maio de 2019.

SILVEIRA, Thais Hae Ok Brandini Park. O Plano Real e o balanço de pagamentos do Brasil. 2015. Tese (Doutorado em Direito Econômico e Financeiro) - Faculdade de Direito, Universidade de São Paulo, São Paulo, 2015.

SIMMONS, Beth. The International Politics of Harmonization: The Case of Capital Market Regulation. In. International Organization. Vol. 55. $\mathrm{n}^{\mathrm{o}}$ 3. Georgetown University: Washington D.C. 2001. pp 589-620.

SIMONSEN, Mario Henrique. Nota sobre o problema inflacionário em 1974. Arquivo Geisel. CPDOC. Dossiê EG/pr 1974.03.28 (I-4). Despacho sem data. 1974.

SIMONSEN, Roberto \& GUDIN, Eugênio. Desenvolvimento: O debate pioneiro de 1944-1945. Vol. 1. Brasília: IPEA. 2010.

SINGER, Paul. Curso de introdução à economia política (Aulas no Teatro de Arena, São Paulo, 1968). 8ª ed. Rio de Janeiro: Forense Universitária. 1983.

SMITH, Adam. A Riqueza das Nações: Investigação sobre sua natureza e suas causas. Vol. 2. Coleção Os Economistas. São Paulo: Nova cultura. 1996.

STN. Relatório Mensal da Dívida Pública Federal. Brasília: Secretaria do Tesouro Nacional. Março de 2018. 
SUPLICY, Eduardo Matarazzo. (1974). Os efeitos das minidesvalorizações da taxa de câmbio sobre as exportações brasileiras. Revista de Administração de Empresas. Vol. 14. $\mathrm{n}^{\circ}$ 6. pp. 33-72.

TAYLOR, John B. Discretion versus Policy Rules in Practice. in. Carnegie-Rochester Conference Series on Public Policy. Vol. 39. 1993. pp. 195-214.

TESCHKE, Benno. The Myth of 1648: Class, Geopolitics, and the Making of Modern International Relations. Londres: Verso. 2003.

TOBIN, James. A Proposal for International Monetary Reform. in. Eastern Economic Journal. Vol. 4. n. 3-4. 1978. pp. 153-159.

VASCONCELLOS, Marco Antonio Sandoval de. Economia: micro e macro. $4^{\mathrm{a}}$ ed. São Paulo: Atlas. 2007.

VEIGA FILHO, João Pedro da. Reformas e projectos monetarios no Brazil. In. Revista da Faculdade de Direito de São Paulo. v. 13. São Paulo: Faculdade de Direito de São Paulo. 1905. pp. 135-153.

VIDAL, Jean-François. International Regimes. in. BOYER, Robert \& SAILLARD, Yves (Org.). Régulation Theory: the state of the art. Londres: Routledge. 2002. pp. 108-114.

VITALI, Stefania; GLATTFELDER James B., BATTINSTON Stefano. The Network of Global Corporate Control. In. PLoS ONE. Vol. 6. 10 a ed. Outubro de 2011.

WALLERSTEIN, Immanuel. O sistema mundial moderno. Vol. I: a agricultura capitalista e as origens da economia-mundo europeia no século XVI. Porto: Ed. Afrontamentos. 1974.

WALTZ, Kenneth. Man, the State and War: A Theoretical Analysis. Nova Iorque: Columbia University Press. 2001.

WEBER, Max. Economia e sociedade: fundamentos da sociologia compreensiva. Vol. 1. 4 a ed. Brasília: UnB, 2000.

WEBER, Max. História geral da economia. São Paulo: Mestre Jou. 1968.

YAMAGUCHI FERREIRA, Caio Rioei. Dívida pública e gestão da liquidez: uma análise a partir de 1994. Tese de Doutorado. Faculdade de Direito. Universidade de São Paulo. São Paulo. 2018. 
ZAHLER, Roberto. La integración a los mercados financieros internacionales: consecuencias para la estabilidad macroeconómica y el crecimiento. Série macroeconomía del desarrollo. ${ }^{\circ}$ 114. Santiago: Nações Unidas. 2011.

ZAKARIA, Fareed. The Rise of Illiberal Democracy. In. Foreign Affairs. Vol. 76. $\mathrm{n}^{\circ}$ 6. Nova Iorque: Council on Foreign Relations. 1997. pp. 22-43. 